\title{
The Ambiguity of Work: Work Practice Stories of Meaningful and Demanding Consultancy Work
}

I Didde Maria Humle'

PhD, External Lecturer, Department of Organization, Copenhagen Business School, Denmark

\begin{abstract}
This article contributes to the current debate among organizational and work-life researchers on the double-sided nature of knowledge work, which offers great freedom and satisfaction on the one hand and the potential to be overly demanding and stressful on the other. This contribution involves drawing on the results of an ethnographic case study of a consultancy house; more specifically, it comprises an exploration of the narrative identity work of consultants as they perform work practice stories of self, work, and the organization negotiating why the work they do is both challenging and rewarding. The type of knowledge work explored is characterized by its immaterial nature in the sense that the primary input is the competences, knowledge, and commitment of the consultants and the output is the joy, success, and satisfaction of candidates, clients, and collaborators. The article contributes by showing that some of the elements perceived to make the work meaningful and rewarding are the same ones also described as potentially demanding and challenging. Furthermore, the article contributes by arguing that studying work practice stories as (ante)narrative identity work provides a rich source of empirical material in the examination of how we create meaning in relationship to the work we do and the organizations by which we are employed.
\end{abstract}

\section{KEY WORDS}

Knowledge work / consultants, work practice stories / narrative identity work / antenarrative storytelling / meaning of work

\section{Introduction}

his article contributes to an ongoing debate among organizational and work-life researchers on the complexities and double-sided nature of immaterial knowledge work. This is done by drawing on the results of an ethnographic and narrative study of a human resources (HR) consultancy house that explores the narrative identity work of consultants as they attempt to make sense of their work-life experiences by sharing stories of self, work, and the organization.

There is no consensus on how to define knowledge work in organizational and work-life studies. Some researchers focus on the immaterial aspect of the work, others on the creative aspects, and still others on how knowledge workers primarily work with tasks connected to information and development (Buch et al., 2009). Alvesson (2000) describes knowledge-intensive companies as organizations where most of the work is of an intellectual nature and where the majority of the employees are highly educated. This is also where qualified products and services are produced primarily through the

\footnotetext{
${ }^{1}$ E-mail: dmh.ioa@cbs.dk
} 
knowledge of the employees. The focus of this article is on immaterial knowledge work, "characterized by non-material input and output, with the individual as the primary bearers of knowledge" (Ipsen \& Jensen, 2012).

Many scholars interested in the work life of knowledge workers argue that there is a close relationship between identity and carrier among knowledge workers (Alvesson, 2000; Buch et al., 2009). Knowledge workers are met with expectations of being dedicated and hardworking (Alvesson, 2000) employees and perceiving work as a source of self-realization, joy, and personal development (Buch et al., 2009). Work done by knowledge workers is often perceived and described as rewarding, offering the employees a meaningful and personally developing work life with exciting challenges, and historically, knowledge work has not been considered to be strenuous or burdensome work (Ipsen, 2006). New studies, however, focus on the complexities and doublesided nature of knowledge, arguing that the working conditions of knowledge workers contain the risk of comprising massive workloads, stress, and burnout (Blair-Loy, 2009; Ipsen, 2006). Thus, attention has been turned toward the complexities and dilemmas experienced by many knowledge workers and the work life of knowledge workers as being filled with dilemmas and tensions (Buch et al., 2009), complexities and contradictions (Mallett \& Wapshott, 2012), paradoxes (Gotsi et al., 2010), ambivalence (Robertson \& Swan, 2003), arbitrariness (Alvesson, 2001), and a state somewhere between excitement and enthusiasm (Buch et al., 2009; Ibsen, 2006).

One important theme in the literature on knowledge work is the balance between work and private life. Many knowledge workers experience flexible working conditions that are often associated with the opportunity to create balance between work and family and to better comply with the demands of family and private life. Studies show, however, how knowledge work and flexible working conditions are often associated with greater responsibility and heavier demands put on the individual, thus making it difficult to balance work and non-work (Blair-Loy, 2009; Ipsen, 2006). Blair-Loy argues that flexible working conditions do not necessarily solely make it easier to comply with the demands of family life. Her study shows how bureaucratic rigidity and a fixed work scheduling can serve as a buffer from the pressure put on workers by customers, thus making it easier for the individual to navigate in a potentially borderless work life (Blair-Loy, 2009). Other studies focus on the expectations put on knowledge workers to be committed and hardworking, arguing how individualized requirements regarding responsibility and engagement in knowledge work are often measured by the amount of time employees are willing to spend at work (Grosen \& Gnudsen, 2003; Hochschild, 2003). Hochschild's (2003) extensive ethnographic study of work-life balance-related issues in a large American corporation shows how management often measures the commitment of employees by their willingness to work long hours, resulting in a situation where many employees ended up with a reversed balance between work and family, making work their primary concern and the most time-consuming aspect of their lives.

Others focus on the immaterial nature of some forms of knowledge work as a potentially stressful and demanding circumstance (Ipsen, 2006; Pedersen, 2008b). In a large study of five engineering consultancies, Ipsen (2006) focuses on knowledgeintensive companies where both the input and the output of the work performed are of an immaterial nature, primarily produced based on the experiences and competencies of the employees. On the basis of her study, Ipsen (2006) describes knowledge work as challenging, complex, independent, and responsible, offering freedom and a high level 
of gratification for employees, but she also identifies several potential problems such as long working hours, conflicting job requirements, loneliness, unpredictability, and unsatisfying knowledge sharing, as well as feelings of guilt, of not performing well, and of always being behind.

Alvesson (2001) accentuates the difficulties involved in evaluating the work of knowledge workers and the complexity this adds to the management of knowledge workers, but also highlights how the close client relationships of many knowledge workers make matters of work identity, organizational identity, and image prevalent managerial and organizational concerns in knowledge-intensive companies (Alvesson, 2000, 2001). Robertson and Swan (2003) similarly point to the difficulties of managing knowledge workers, particularly in balancing matters of control and influence and in making room for differences and the ambivalent emotions of knowledge workers. Related to these issues, another condition of modern work life and particularly of immaterial work is an increased detachment of work from the institutional boundaries of time and place (Kamp et al., 2011; Pedersen, 2008b). Many people are now able to work whenever and wherever, and studies show how the self-management of time has become a central task of modern work life and how this, combined with high demands concerning the level of commitment and the increased complexities of work, makes the boundaries of work a difficult, individualized concern of many workers, particularly knowledge workers or others doing immaterial and relational work (Kamp et al., 2011; Pedersen, 2008b).

This article contributes to the debate on the double-sided nature of knowledge work and the complexities of being a knowledge worker by drawing on a narrative and ethnographic case study of a HR consultancy house that works in different areas to bridge people and work (e.g., recruitment, HR services, and assisting the unemployed in their job search). The type of work explored is knowledge work in the sense that primarily the experiences and competences of the consultants constitute the product presented to customers and job seekers. The input and output of the work the consultants perform is immaterial, while simultaneously being characterized by a close and constant interaction with many different people, e.g., customers, candidates, colleagues, and collaborators, who do not always share the same preferences and goals. This makes the case interesting from the perspective of studying both the potentially satisfying and demanding aspects of immaterial knowledge work. The contribution made is twofold; first, it contributes to a greater understanding of the complexities of performing immaterial knowledge work and of accommodating all the various work-life demands, not to mention the obligations of non-work. Second, it is argued that close examination of the (ante)narrative identity work and the complex way in which consultants constantly work to make sense of their work-life experiences by telling stories of self, work, and the organization as a web of interrelated storytelling performances are a fruitful way to explore the work life of knowledge workers and the tensions and paradoxes experienced in their work.

\section{Performing stories of self, work, and the organization}

In recent years, narrative organizational research has increasingly focused attention on the polyphonic, dynamic, and collective aspects of organizational storytelling (Belova et al., 2008; Boje, 1991, 1995; Hazen, 1993; Vaara \& Tienari, 2011) as well as on the narrative identity and sensemaking construction processes (Belova, 2010; Cunliffe \& 
Coupland, 2012; Humphreys \& Brown, 2002; Linde, 2001, 2009; Pedersen 2008a) as they emerge in and around organizations. I build on this body of literature and contribute by combining Sveningsson and Alvesson's (2003) concept of identity work with narrative identity theory (Cunliffe \& Coupland, 2012; Cunliffe et al., 2004; Driver, 2009; Humphreys \& Brown, 2002; Linde, 2001, 2009; Mishler, 1999; Pedersen, 2008a) and Boje's work on storytelling and antenarrative storytelling. I argue that one way to study the work life of knowledge workers and the complexities and tensions of knowledge work is through work practice stories of work, self, and the organization (Driver, 2009). The focus of the analysis presented is on the narrative, performative, collective, and dynamic aspects of constructing self in relation to everyday work experiences. I propose that one way of conceptualizing work identity in narrative, performative, relational, and dynamic terms in an organizational context is the concept of narrative identity work. Introduced by Sveningsson and Alvesson (2003), the concept of identity work "refers to people being engaged in forming, repairing, maintaining, strengthening or revising the constructions that are productive of a sense of coherence and distinctiveness" (2003: 1165). Their approach emphasizes “(...) dynamic aspects and on-going struggles around creating a sense of self and providing temporary answers to the question 'who am I' (or 'who are we') and what do I (we) stand for?" (p. 1164). In this framework of understanding, both individual and organizational identities are better understood as becoming rather than being. Sveningsson and Alvesson (2003) also argue that, individuals strive for comfort and meaning and also for some form of correspondence between self-definition and our work situation.

Inspired by Pedersen (2008a) and building on narrative theory, I suggest the concept of narrative identity work, thus turning my attention toward the narrative, collective, dynamic, and performative aspects of identity work. Goffman (1959) elaborates on the performative aspect of identity and argues that identities are situated and accomplished with audience in mind and performed to create positive self-representations. Similarly, Mishler (1999) claims that stories of work and work-life stories can be viewed as narrative identity accomplishments or constructions of self-understanding. He argues that we are constantly adjusting and regulating our identity stories in order for them to make sense to ourselves and others. At the core of this conception is the notion of identity as narrative constructions. This means that we construct our identities by telling stories of who we are and who we want to be. With these stories, we create coherence and meaning in relationship to what we encounter in the course of our daily lives. Similarly, Cunliffe et al. (2004) and Cunliffe and Coupland (2012) view narratives and storytelling as crucial parts of identity work and argue that we make sense of situations on "a moment-to-moment basis and in different circumstances by presenting a range of narrative performances" (2012: 70). Building on the work of Cunliffe et al. (2004), and inspired by Ricoeur's work, Cunliffe and Coupland (2012) argue that narratives are not necessarily deliberate or coherent; often they are spontaneous acts of making sense of our experiences produced in interaction and conversation with others. In this way, stories are contested and responsive performances and we are simultaneously enacting and modifying meanings and narratives, “(...) by perpetually drawing on past events and conversations, present interactions, and by anticipating future events and actions" (Cunliffe \& Coupland, 2012: 67).

Boje (1991) emphasizes the performative, collaborative, and contextual aspect of organizational storytelling, arguing that in the daily course of our lives we use stories to 
create meaning but also to handle the challenges we face. Boje argues against the tradition of working with stories as texts separated from their natural setting, because this means the performative aspect is ignored and that no insight is gained into the complex, dynamic ways in which organizational members use the telling of stories in relationship to their work context. To capture the often emergent and unstructured nature of organizational storytelling, Boje $(2001,2006,2008,2011)$ proposes the concept of antenarrative storytelling by which he directs our analytic attention to "the flow of the storytelling" (2001: 4). Boje defines antenarratives as "the fragmented, non-linear, incoherent, collective, unplotted, and pre-narrative speculation, a bet, a proper narrative can be constituted" (2001: 1) and claim that "they are 'in the middle' and 'in-between' refusing to attach beginning and endings needed to achieve narrative closure" (2006: 40). Furthermore, antenarratives form clusters of shared meanings and are intertextually related across places and times (Boje, 2001). Boje uses the notion of living story networking to describe how "a person's story denotes or implies between the lines relationships to other stories" (2011: 14). In this vocabulary, the antenarrative storytelling of organizations can be seen as a web of storytelling episodes intertextually related and performed by members of organizations across time and space as they collectively work to make sense of everyday organizational life. Also, the concept of antenarrative allows us to work with retrospective, here-and-now and prospective sensemaking as dynamic and collective sensemaking processes and with the multiple pasts, presents, and futures (Jørgensen in Boje, 2011) of the many simultaneous and polyphonic organizational dialogs.

Seeing the work practice stories of consultants as creative constructions of self, work, and the organization is inspired by the work of Driver, who argues that stories are "lived practices of creative performativity" (2009: 365). She examines how stories of change serve a dual function in "allowing storytellers to construct the organization, work, and self in imaginary ways but also importantly to encounter the failure of such constructions"(Driver, 2009: 362). Similarly, this article studies the work practice stories performed by the consultants to explore the dual functions of these stories of work, self, and the organization. Thus, I explore the ongoing narrative identity work of the consultants as they struggle to define themselves in relationship to the work that they do and the organization by which they are employed, constantly finding temporary answers to questions of "'who am I' (or 'who are we') and what 'do I (we) stand for'?" (Sveningsson \& Alvesson, 2003: 1164). Moreover, I propose that the ongoing narrative identity work of constructing self, work, and organization in meaningful and imaginative ways to portray positive self-representations (Goffmann, 1959) is antenarrative (Boje, 2001, 2006, 2008, 2011 ) in the sense that it is never finished or complete. There is no narrative closure to the stories of self, work, and organization. The sensemaking is ongoing, not only because employment is an institutional membership always open for consideration (Linde, 2009) but also because the work of creating meaning and identity in relationship to work is an ongoing process of creating contested and responsive narrative performances (Cunliffe \& Coupland, 2012; Mishler, 1999).

Adopting the antenarrative vocabulary makes it possible to study all types of utterances, for example, statements, descriptions, full-blown retrospective narratives (with beginning, middle, and end), and fragments of stories as part of the ongoing story work of organizational members as they go about making sense of and constructing self, work, and the organization in different ways. As a result, all types of utterances have narrative qualities and are seen as part of the narrative identity work of constantly 
finding temporary and plausible answers to the questions of who am I and who are we. Simultaneously, all the different types of utterances are part of the web of organizational storytelling connecting organizational members in dynamic clusters of shared meanings and understandings, for example, as in the analysis presented in this article about what makes the work of a consultant meaningful and of what it means to do work well. Thus, all utterances are potentially fragments of storytelling and require no standard structure involving lines of events or plots; they become stories as they are told to create meanings. Consequently, storytelling happens by storytellers and their attempt to create meaning, often by describing fragments of time, characters, and events, but not necessarily in chronological order and with various times and understandings of events.

\section{Method and analytical reflections}

The empirical material used for this article is based on one case company, a consultancy house that works to bridge people and work (e.g., recruitment, HR services, and assisting the unemployed in their job search). Conducted by the author of this article, the fieldwork took place from 2008 to 2010. During the fieldwork, the consultancy underwent multiple organizational restructurings due to changing markets and circumstances. Thus, the number of employees varied from approximately 100 to 150 spread out across 10 to 12 offices around the country. The empirical material, a combination of narrative interviews and ethnographic studies of everyday life in and around the organization, also includes documentation primarily comprising posts on the company intranet and group e-mails. About half of the researcher's time was spent at the company collecting stories and posts on the company intranet, visiting the different departments and attending meetings, lunch breaks, gatherings, and teaching, in addition to simultaneously interviewing consultants.

Thirty-two semistructured narrative interviews (Czarniawska, 2004) were conducted with two types of consultants: 1) job consultants who assisted with unemployed candidates and 2) personnel consultants who worked with recruitment and related HR services. The narrative interviews lasted 1-2 hours and were all transcribed. Inspired by the Critical Incident Technique (Czarniawska, 2004; Flanagan, 1954), the interview guide was designed to promote the telling of everyday work practice stories by consultants and included questions such as "Can you tell me what you did yesterday?" "Can you tell me about a situation where you felt you did your job well?" and "Can you tell me about a situation where you did not feel you were able to do your job well?" The interview guide was semistructured in the sense that additional questions were always asked and other situations observed or experienced (the consultants work, meetings, gatherings of the company) were also discussed and elaborated on by the consultants.

All the material was collected and analyzed continuously using a dialogical interpretation process of going back and forth between theory, method, and the field (Renemark, 2007; Thisted, 2003). The advantage of this explorative and abductive process is that the insights are not gained from testing theory or from the empirical material alone, but instead from using theory with the data in different ways (Cunliffe \& Coupland, 2012). In this way, the analysis and the carrying out of the interview were informed by the ethnographic fieldwork. With regard to the performative aspects of the narrative identity work of the consultants and of how the consultants address and perform the notions of 
self, work, and the organization, the analysis undertaken focuses on the construction of self and others and the emotions attached to the stories. This does not imply, however, that the interview situation is viewed as a window for understanding organizational life or the inner emotions of the consultants. Taking seriously the constructivist and performative understanding of language as a "productive, performative, proactive constructor of the social world" (Svensson, 2009: 168), the interview is a place of recreation rather than representation: "(...) the interview is seen, not as a report of a certain state of affairs in an external organizational reality, or of inner mental realities, but as an active mode of organizing and putting together a plausible version of reality (one that makes sense here and now, in the interview situation)" (Svensson, 2009: 174).

The interview consequently becomes an interesting social interaction in itself, not as a representation of organizational life or as an attempt to understand what actually happened in the situations narrated; instead, the talk is of interest because the consultants are engaged in actively constructing different possible versions of self in relation to organizational life. Reflecting on the nature of the interaction in the interview, however, is still relevant. By asking certain questions, the interviewer sets the scene of the interview and thus becomes an active co-constructer of the stories shared by informants (Czarniawska, 2004; Mishler, 1999). According to a constructivist and performative approach as well as Boje's (1991) understanding of stories as collectively constructed performances, stories are always co-constructed acts. In this optic, it is not interesting to ask questions about whether the consultants are making accurate or truthful descriptions; instead, it is of interest to study how the consultants work, through language as a productive and performative activity, to construct different possible versions of organizational life. In this study, the conversations between the researcher and the consultants often reached beyond the borders of the interview. Spending time at the various offices and attending many different kinds of organizational activities made the interview more integrated and less separated from the work life of the consultants. It also provided the opportunity to relate the interview to other organizational dialogs and storytelling occasions. One advantage of conducting interviews is that they create a break in organizational life, providing the space for making reflections, telling stories, and performing different possible versions of self, work, and the organization.

The analysis presented in this paper is a combination of thematic and performative narrative analyses (Riessman, 2008). This means that the focus is not only on performativity-related aspects, such as the context and issues revolving around how and why the stories are shared, but also on thematically relevant aspects, such as the content of the stories and what the consultants talk about when they tell stories of work (Riessman, 2008). In the performative analysis, close consideration is paid to the context and how talk between individuals is produced and performed as narratives. This made it possible to explore how important work practice themes are constructed and reconstructed differently from moment to moment in the story work of the consultants. The thematic analysis also adds to contextualizing the stories in the organizational setting of the consultancy house because the thematic analysis across interviews shows how the individual story performances are related to each other and are intertextual across places and times (Boje, 2001). Thus, to contextualize the individual narrative identity work of the consultants, I have explored how all the stories and story fragments are intertwined, forming clusters of shared meaning and referring to the same themes. This was done by rereading the material over and over again and asking myself: What do the 
consultants talk about when they talk about their work and about how and when it is perceived as being rewarding and meaningful? Are there central themes or shared conceptions that are more prevalent and persistent across time and space than others? Three important work practice story themes emerged during this process: 1) doing work that makes a difference, 2) the quality of work, and 3) having success. Although separated for the sake of presentation, hopefully their intertwined, interrelated, and unfinished (unclosed) nature remains apparent.

\section{Results}

The analysis presented below explores the narrative identity work of consultants as a web of storytelling episodes constructing, reproducing, and negotiating different notions of why and how work is meaningful and rewarding. The analysis is divided up based on three prevalent work practice themes persistently performed and negotiated across time and space: 1 ) doing work that makes a difference, 2) the quality of work, and 3) having success. It sheds light on not only how many different considerations and demands are constantly present in the construction of self, work, and the organization but also the many different organizational storylines and shared notions that are present. The particular case company has a tradition of sharing positive work practice stories about success, collaboration, and the meaningfulness of making a genuine difference in the lives of others. Such positive stories are shared on many different organizational storytelling occasions, for example, the company intranet, customer meetings, and company gatherings. In addition, as part of their work practices, the consultants are expected to present, narrate, and enact positive images of the company and its products (the work of the consultants) toward candidates, collaborators, and customers. These organizational storytelling practices are reflected in the story work of the consultants, where positive organizational storylines of having fun while working hard are prevalent and easily performed. However, the analysis also illustrates how the work practice themes are simultaneously constructed by displaying tensions and presenting critical organizational counterthemes of, for example, not having enough time and being overwhelmed by work.

\section{Doing work that makes a difference}

One work practice theme persistently performed across storytelling occasions is that making a genuine difference makes this type of work meaningful and rewarding. In the empirical material there are many stories about helping, encouraging, and making a difference in the lives of job-seeking candidates. Some of these candidate stories, such as the one presented below, are dramatic retrospective narratives characterized by a richness and almost epic form of representation; however, there are also less dramatic, less specific story performances about, for example, asking the right questions, being able to see options not immediately visible to the candidates or customer, and about helping companies find just the right candidate. When asked to describe a work situation where he was able to perform his job well, one consultant told the following story: 
'For me, it often happens when I'm doing something that isn't even my job, that is, when I do something extra special. When it has nothing to do with getting paid, or my job or what it says in my contract, but when it's purely human things. For example, we were working with a candidate once who had been fired. He was a single dad with a son and he suddenly became seriously ill while he was in our program. (...) He didn't have any money and no network. I gave him a voucher and the other consultants and the chief consultant also started to help. It's one of the coolest experiences I've had at this job. Martin (a colleague) filled out a transport application for the municipality. Peter (the boss) contacted another colleague of ours from the town of Gladsaxe and arranged transport to appointments at the hospital. At that point, he (the candidate) was ready to give up everything. There's something about doing what's right, just doing what's right, then I do my job well, when I do it right. I still talk to him. He's started working again, his treatments are over and he has been declared healthy. If things had happened differently, he would have become paralyzed because he didn't have anyone. Just us helping a little. We drove out to his house with the application, then went to the municipality and said "this is urgent". It didn't take much. It's amazing how much just a small gesture can mean. Being involved in that was great.' (narrative interview, consultant)

In the stories that refer to the theme of making a difference in the lives of others, there is often a positive, easily narrated correspondence between a self-definition and work situation (Sveningsson \& Alvesson, 2003). Moreover, the consultants can present the organization as a meaningful context for their daily work and the emotions attached to these stories are positive, often expressed as pride or joy in being able to help others. However, as in the example presented, tensions between doing the right thing and the financial results are often an underlying subtheme, thus illustrating how storytellers simultaneously address more than one organizational storyline. This storytelling episode is about more than just making a difference in the lives of others. The author is simultaneously addressing a central organizational dialog related to the output of the work of the consultants, contrasting the immaterial output often accentuated by consultants, such as joy, success, and the satisfaction of candidates, clients, and collaborators, and more measurable outputs often accentuated by management, such as financial results, the number of client meetings, and conversations with candidates.

As in the quote above, doing something extra that is not an inherent part of the job description or necessarily expected of the consultants is often presented as an important element of performing well. In this way, the extra effort and commitment of the consultants is frequently used as an evaluative comment prescribing meaning to the events narrated (Riessman, 1993). Another consultant finishes her story about a time when she felt like she did her job well with this description, "Well, it was nice. Of course it's also nice when people get a job, but I always think it's nice when I put in an extra effort, because technically it isn't something we get paid for." Again doing something extra special is constructed as being opposite to the financial outcome or what is in the job description. When narrating stories related to the theme of making a difference, other tensions often appear. Two central concerns are that helping people and/or solving their problems is not always achievable and the other is that the constant contact with many different people can be a highly strenuous, demanding aspect of the consultants' daily work. One consultant explains, "You're in contact with a lot of people in one day. You 
feel used up when you get off work and get exhausted after so many conversations (...)." And another states:

'I have an hour to get everything out of a person, so there's a certain amount of pressure when you have four of them in the course of one day, which leaves me feeling completely beat. I just can't take in more people (...) On the days when I have a lot of interviews, I'm tired and I don't have any energy left for my children.' (narrative interview, consultant)

These story performances of the strenuous nature of everyday work are often more fragmented. The candidates and customers appear as "a lot of people" and something that just cannot be taken in. The meaningfulness of the daily work of the consultants is challenged by its influence on non-work, and the image of self, work, and the organization becomes less coherent and harmonious. In these types of stories or story fragments, work takes the form of something overly demanding and the relational aspect of the work becomes a negative, demanding circumstance opposed to the positive conception of making a difference in the lives of others. The emotions attached to the stories by the narrator are regularly described with words like "tired" or "drained" and a sense of despair is often expressed in connection with having to portray oneself as someone who is exhausted by work and who does not have enough energy left over for matters outside of work, for example, friends and family.

\section{The quality of work}

Closely connected to the shared conception that work is meaningful and rewarding when making a difference in the lives of others is the insistence on quality or on doing work well as an important prerequisite for meaningful work:

'I've always said that I want to be able to look myself in the eye. Well, it's just a good feeling and that's important to me. I want to do my things well and it's really great when I succeed, and in relation to customers, well, I don't want to promise them too much. It's partly that feeling of anxiety about not being able to live up to it; that haunts me too. Then they get angry. I want to do my job well and I want others to think so too. I had a job challenge that went poorly and after three months we decided that it hadn't succeeded, and I think that I fought incredibly hard. (...) It's been a tremendous challenge for me, but it's awfully annoying to determine that after three months it just didn't work. But, actually, because I knew that I had done what I could, that I had made an effort and really tried, well, then I can't do more.' (narrative interview, consultant)

This example illustrates the ongoing, temporal process of making sense of our work lives and ourselves (Cunliffe \& Coupland, 2012). The consultant is negotiating with herself about the relationship between doing things well and succeeding. She portrays herself as someone who wants to do things well and who wants to be able to look herself in the eye. She is anxious about not being able to do well and of making people angry. Doing the right thing is introduced as a way of navigating between all the different demands and expectations of everyday work and connects the story to many other story performances, for example, the story about helping a sick candidate presented above. The conception of 
doing the right thing is a recurring theme in the consultants' stories and the similarities between the ways the theme is used indicate the creation of shared meanings and show how consultants' story performances are related across time and space (Boje, 2001). Also, the example presented here illustrates the extensive story work that goes into narrating failure. Many considerations are at play, such as financial results, satisfying customers, being able to "look myself in the eye," "do my job well," and have others "think so too," and the work is connected to diverse emotions such as "a good feeling," anxiety, and anger. Performances where work is at once both potentially extremely satisfying and upsetting are not uncommon in the empirical material and expressions of ambiguity posed by tensions between management discourses, official organizational storytelling, and everyday work experiences are often present in the story work of consultants. This is the case in the following example, where work is constructed as something the consultant "loves" and as overly demanding:

'I had a really busy period last summer when I was here alone. Orders poured in and it's fantastic, I love my job, but you can only handle a certain amount of work and the day turns out not to be good if you've suddenly been at work for 12-14 hours and you've done that for many days. At some stage, the air goes out of the balloon and you can't do more. Then it's not fun. And when your boss doesn't even call or is impossible to get a hold of, then you haven't had a good work day.' (narrative interview, consultant)

Constrained by the request to describe a less than positive work day, the consultant begins a tough story about a busy period in which she worked alone 12-14 hours a day, and her boss was out of reach. She suddenly interrupts herself with the phrase: "Orders poured in and it's fantastic, I love my job." In this way, the example illustrates how the official stories and storytelling practices of the organization influence the narrative identity work of consultants. In the positive storytelling "community" posing critique toward management and displaying negative emotions toward work is not necessarily easy. In this example, the consultant is not able to tell her story of a negative work experience without simultaneously performing positive storylines of how much she loves her work. In her story work, she is handling many different demands and expectations, not by introducing a clear causality between them, but by allowing tensions and by introducing many different potential storylines, for example, of being a dedicated and hardworking person who loves her work, of what a god/bad work day is, of what a boss is supposed to do, of how much energy and time one should invest in work, and in fulfilling the goals of the organization.

The example is connected to a broader organizational dialog regarding the relationship between time, resources, and quality and how much time and energy one should invest in work to ensure quality. In the work practice stories of the consultants, the notion of quality is often most explicit in stories of situations or periods where there is a lack of quality. One consultant narrates a busy period as follows: "I simply had too many tasks, which meant less quality and I couldn't keep up. I hate it when I don't manage to get out and say hello to the candidates. Things need to be in order. We have to keep our promises. Otherwise the quality is poor." Connecting the lack of quality to a shortage of resources creates a tension between self, work, and the organization. The organization is no longer portrayed as a meaningful work community that allows the consultant to perform meaningful and rewarding work. The use of the words "hate" 
and "keeping our promises" reflects the seriousness of the emotions expressed. Narratively performing herself as someone who insists on doing work well by ensuring that things are done right allows the consultant to deal with the failure of the construction of coherence between a positive self-representation and her work situation. The story performance is also an example "of what is not said and yet shared" (Boje, 1991: 107). By ending her performance with the word "otherwise the quality is poor," the consultant is not only portraying herself as someone who insists on quality, she is also making a reference to the shared notion that this is a company that insists on doing things well and ensuring that customers always receive quality. Thus, the consultant is referring to shared references and organizational dialogs concerning the quality of work and simultaneously making a serious statement that quality is not always accomplished.

\section{Having success}

Having success is the third work practice theme often referred to by consultants when addressing the meaningfulness of the work performed:

'It's great and the cool thing about this job is when you succeed, when things go well and the recruitment has gone through and everyone is happy. It's really nice to talk to the candidates who have just signed a contract and quit their job and they're just happy and excited. And the company is happy, everyone is happy and we can send out an invoice.' (narrative interview, consultant)

In this moment of narrative identity work, succeeding is primarily associated with making everyone happy. However, at the end of this narration, the financial aspect is also accentuated, "we can send out an invoice." As a result, the consultant makes a reference to the conception regularly performed by both members of the management team and consultants, that is, making money is important. The success stories do not necessarily contain a contradiction between the financial results and the success of the situation. However, as with stories about making a difference in the lives of others, doing the right thing, considering the human aspect, being true to one's values, or making people happy often take centerstage. Stories of collaborative success are a type of story often presented on the company intranet:

'I was at a customer's on Wednesday to get a rush job. It was to cover a maternity leave and, optimally, the person had to start within 7-10 days. Whew, the pressure was on but that's cool. For those of you who don't know me, I can tell you that I thrive when there's a fast pace and short deadlines. I looked at our candidate database and asked colleagues for advice. Mia had just interviewed one of Thomas' candidates and she was suitable for the job and quite interested in it. Morten had an outplacement candidate who might be interested. These two were the most suitable and the only two being interviewed by the customer today. He liked both of them, but had to settle for one. This makes working together fun.' (Company intranet, consultant)

By connecting the success of the situation to having fun and collaborating with colleagues, the consultant is able to present herself as successful and as someone who 
enjoys working fast and having short deadlines without overestimating the importance of her own performance. At the same time, she draws on organizational discourses or mutually shared conceptions on the importance of collaboration, working fast, and making an extra effort to ensure success and create the perfect match between company and candidate. This is done nearly seamlessly and with little effort, indicating the integrated and prevalent nature of such conceptions in this particular organizational setting. This consultant has learned to tell her stories as part of the organization in a way that makes it possible for others to relate to her story without much effort or knowledge of the specific situation.

Because of the positive emotions attached to situations of success, the organizational emphasis on the importance of being successful, and the many success stories, the stories of failure are often fragmented and personal. In this way the stories of not being able to perform successfully are generalized and fragmented stories displaying the extra effort and positive commitment described in the success stories in the negative form of overinvolvement and expressing emotions of despair and sadness. In the following quote the consultant addresses the line of business and the immaterial nature of the work as potentially demanding aspects of everyday work. Also she is narrating the tension between success and failure and the ambivalence often expressed in handling all the different demands of everyday work:

'It's a very hard core industry. This applies to the entire industry, also this company-it's not true that we're different; the entire temporary employment industry is like this. They say that if you can handle the temporary employment industry, you can handle anything. I'm fine with sales, which is something you constantly do in this industry. That's what I like about it, the fact that it deals with relationships; I'm not selling a tangible product. I can't say it's pink and looks like this or this. It's my credibility that sells, the fact that they trust me to find the right person. I actually really like that and that's what my reputation depends on. (...) Ninety percent of the time everything goes alright, but it's the ten percent that makes this a difficult brand and people don't necessarily speak nicely. When expectations aren't met, people get frustrated (...) and of course that frustration gets directed at us, which is why it's important not to take it personally. The people that can keep everything separate do really well. For someone like me, who is very empathetic, puts their heart into it and who wants everything to be successful, then it can be very difficult (...).' (narrative interview, consultant)

The consultant is creatively negotiating the meaning of the immaterial aspects of her work. On the one hand, she likes the fact that what she is selling is herself and her own credibility. On the other hand, selling oneself appears to be potentially hard work that makes distancing oneself from work difficult. The story performance illustrates the fine line between aspects of the job being narratively performed as rewarding and as potentially overdemanding. Selling herself and her expertise as a consultant is in the same story performance episode performed as something that she "really likes" and something that can be "very difficult" to handle. As in this example success is often closely connected to positive self-representations and constructed as a personal desire and important goal. Being the primary input of this type of immaterial work is performed as desirable and as something the consultants would not do without. However, as in this example, selling oneself is potentially hard work because the potential failure thus becomes a personal 
failure. The imaginative and associative nature of narrative identity work is well demonstrated in this story performance. Many considerations and organizational dialogs are at play and many hints are made. For example, the statement "It is not true that we're different" is a reference to an often shared notion that this company is different from its competitors because values, quality, and the human aspect are never compromised. Also, constructions of self, work, and the organization are made and then torn apart revealing the antenarrative nature of the narrative identity work. Stories of self, work, and the organization are always in the making and never finished or completed in the narrative retrospective sensemaking.

\section{Discussion}

The analysis presented in this article explores the narrative identity work of consultants as they work to make sense of their work-life experiences and construct temporary answers to the questions of who they are and what makes their work meaningful and rewarding. The analysis shows how the consultants creatively construct themselves, their work, and the organization in different ways. It is also illustrated how many considerations always exist that must be taken into account and that much story work is required to navigate between all the different demands and expectations of everyday work. The three work practice themes, doing work that makes a difference, the quality of work, and having success, appear to be contextually embedded and institutionalized in the sense that they have become shared ways of talking about work and organization in this particular organizational setting. These results are similar to Orr's (1996) classic ethnographic study of the everyday work practices of copy machine repair technicians. His study shows how the "war" stories technicians share about how they solve various problems functioned both as distributers of knowledge and to create a sense of community among the technicians. In this sense, the storytelling practices were a central part of how the meaning of work was shared and negotiated among technicians. This is similar to the identity and meaning construction processes among the consultants of this study, where stories of success, of making a difference in the lives of others, and of doing work well were often performed and created shared references, meanings, and a sense of community across time and space.

In addition, the analysis shows how the storytelling practices of the organization influence the individual narrative identity work of the consultants. The particular case company has a tradition of sharing positive work practice stories about success, collaboration, and the meaningfulness of making a genuine difference in the lives of others. The analysis accentuates the tensions between these positive storytelling practices and the performance of more critical or negative storylines. The positive work practice stories are easily performed as positive self-representations portraying meaningful correspondences between self, work, and the organization. The less positive story performances are often more fragmented and personal. However, they too form clusters of shared meanings of why the work situation is not always satisfying and meaningful, of not having enough time and being overwhelmed by work. In this way the analysis accentuates the importance of considering the particular organizational storytelling practices into the study of narrative identity work and sensemaking processes. The numerous stories of success, fun, and commitment and the fact that consultants are expected to enact 
positive images of the company and its products mean that the notion of the dedicated and loyal knowledge worker (Alvesson, 2000; Pedersen, 2008b) determined to create results (Pedersen, 2008b) who desires a work life of constant challenges and development (Buch et al., 2009) is constantly being activated and reproduced by all members of the organization. This is reflected in the narrative identity work of consultants, where negative statements are often less explicit and more fragmented, merely hinting at matters of concern and not fully articulating them. Further negative story performances are often interrupted by strong statements of commitment and enthusiasm about wanting to do the job well and of being willing to work hard. In this regard, the findings correspond well with the results of Rasmussen and Håpnes' (2012) study of seven different knowledge work contexts in Norway. Their study shows that knowledge workers did not leave their jobs because they were profit-seeking portfolio workers but rather among other things because it "(...) was no longer possible to do a good job and they were disillusioned with the company and gave up trying to affect changes (...)" (Rasmussen \& Håpnes, 2012: 19). In a similar way, the consultants of this study collectively insist that in order for work to be perceived as meaningful, it must provide the opportunity to do the right thing, to make a genuine difference, and to perform quality of work.

The analysis illuminates how the relationship between self, work, and the organization is constantly being negotiated in the ongoing story work of consultants. Work is not good or bad, rewarding or challenging, meaningful or meaningless, but potentially all these aspects rolled into one. Similarly, the organization is constantly constructed differently by its members as they make sense of their work-life experiences, not only drawing on mutually shared conceptions and organizational discourses but also creating different images of self, work, and the organization. In this way, there is a constant negotiation between a plethora of different emotions, demands, expectations, conditions, assumptions, and ambitions. Here, the antenarrative approach proved to be fruitful in that it becomes possible to study not only how stories are performed to make sense by creating coherence and causality but also how they simultaneously allow consultants to handle ambiguity, contradictions, and tensions. The analysis shows how each storytelling episode potentially comprises a number of competing storylines and constructions at once, for example, as the female consultant who interrupted herself with the sudden statement: "It's fantastic, I love my job" as she shared her story about an intensely busy period while everyone was on vacation and she had to work 14-hour days as orders poured in and her boss was out of reach. Her story is testimony to how more than one organizational storyline can take place simultaneously, in this case, one about how fun work is and another about how hard work can be sometimes. In this way, the analysis contributes to the understanding of narrative identity of knowledge workers in pointing to the complexities and unfinished nature of constructing self in relationship to this type of work. There are many possible stories to be told and even a small piece of story work potentially contains many different and often opposing storylines.

A recurring topic in the three work practice themes is the relationship between work and non-work and related matters concerning how much time and energy it is reasonable or necessary to invest in work. In the less positive work practice stories, the matter of work boundaries appears to be a central issue of concern. The analysis points to a constant reproduction of the notion that work is most rewarding, interesting, and fun when making an extra effort or being extraordinarily dedicated; also the three central work practice themes are constructed by the extra effort and investment of 
time and energy as well as emotional and personal commitment. In this way notions of the "ideal" consultant as someone who is deeply dedicated toward work and is willing to spend a great deal of time and energy to ensure quality work and the success of the company are constructed. The image of the ideal consultant is constantly being created and recreated by consultants, management, customers, and candidates in their daily interactions. In this regard, the study contributes to earlier studies on the close connections between identity, work, and organization among knowledge workers (Alvesson 2000, 2001; Czarniawska \& Mazza, 2003), showing that they are not solely a result of current management techniques constituting employees as knowledge workers and entrepreneurs (Covaleski et al., 1998).

The study points to many interesting aspects of the immaterial and relational knowledge work to be investigated further. Among these are the difficulties involved in obtaining a sense of consensus on the meaning and quality of work among managers and employees (Alvesson, 2001, 2004) and the difficulties of managing knowledge workers (Alvesson, 2001; Robertson \& Swan, 2003). In the study presented in this paper, the negotiation of quality was an organizational dialog filled with tensions between different considerations and demands. Quality was most visible in stories about the lack of quality and these stories often displayed tensions in the construction of self, work, and the organization, consequently portraying management and the industry as hindering factors and the creation of success and quality as not being a mutual responsibility. In this sense, the study relates to earlier studies accentuating the importance of making room for ambivalence (Robertson \& Swan, 2003) and multiplicities of meanings in managing knowledge workers. To explore these matters further, it would be interesting to conduct similar case studies using the analytical framework of (ante)narrative identity work to further explore the work of knowledge workers, with even closer attention paid to the everyday negotiations of organizational members as they go about their work and construct different notions of self, work, and the organization.

\section{Conclusion}

This article presents the results of an ethnographic and narrative study of a HR consultancy house that explores the narrative identity work of consultants as they attempt to make sense of their work-life experiences by performing stories of self, work, and the organization. The contribution made is twofold. First, the study contributes to a line of narrative research focusing on the interplay between individual and collective organizational sensemaking and identity construction processes as they are played out in the daily storytelling practices in and around organizations. This contribution is made by analytically combining the concept of narrative identity work with Boje's work on antenarrative organizational storytelling to study the narrative identity work of organizational members as a web of antenarrative storytelling episodes. Second, this paper contributes to the ongoing debate among organizational and work-life researchers on the complexities and double-sided nature of immaterial knowledge work, which, on the one hand, is often described as meaningful and rewarding and, on the other, as potentially demanding and stressful. The article contributes to this debate by accentuating the (ante)narrative nature of how the relationship between self, work, and the organization is constantly being negotiated in the narrative identity work of consultants, illustrating 
how work is not good or bad, rewarding or challenging, meaningful or meaningless, but potentially all these aspects at the same time. Similarly, the organization as a place of work is constantly subjected to the ongoing story work of its members as they attempt to make sense of their experiences, drawing on mutually shared conceptions and discourses but also constructing unique and imaginative images of self, work, and the organization.

\section{References}

Alvesson, M. (2000): 'Social identity and the problem of loyalty in knowledge-intensive companies', Journal of Management Studies, 37(8): 1101-1124.

Alvesson, M. (2001): 'Knowledge work: ambiguity, image and identity', Human Relations, 54(7): 863-886.

Alvesson, M. (2004): Knowledge Work and Knowledge-Intensive Firms, Oxford: Oxford University Press.

Belova, O. (2010): 'Polyphony and the sense of self in flexible organizations', Scandinavian Journal of Management, 26(1): 67-76.

Belova, O., King, I. and Sliwa, M. (2008): 'Introduction: polyphony and organization studies: Mikhail Bakhtin and beyond', Organization Studies, 29(4): 493-500.

Blair-Loy, M. (2009): 'Work without end? Scheduling flexibility and work-to-family conflict among stockbrokers', Work and Occupation, 36(4): 279-317.

Boje, D. M. (1991): 'The storytelling organization: A study of story performance in an officesupply firm', Administrative Science Quarterly, 36: 106-126.

Boje, D. M (1995): 'Stories of the storytelling organization: a postmodern analysis of Disney as "Tamara-land", Academy of Management Journal, 38(4): 997-1035.

Boje D. M. (2001): Narrative Methods for Organizational \& Communication Research, London: Sage Publications.

Boje, D. M. (2006): 'Breaking out of narrative's prison: improper story in storytelling organization', Story, Self, Society: An Interdisciplinary Journal of Storytelling Studies, 2(2): 28-49.

Boje, D. M. (2008): Storytelling Organizations, London: Sage Publications.

Boje, D. M. (ed) (2011): Storytelling and the Future of Organizations. An Antenarrative Handbook, New York: Routledge.

Buch, A., Andersen, V., and Sørensen, O. H. (2009): Videnarbejdeog stress: Mellembegejstringogbelastning [Knowledge work and stress: between enthusiasm and strain] Copenhagen: Djøf Publishing, Randers.

Covaleski, M. A., Dirsmith, M. W., Heian, J. B. and Samuel, S. (1998): 'The calculated and the avowed: techniques of discipline and struggles over identity in big six public accounting firms, Administrative Science Quarterly, 43(2): 293-327.

Cunliffe, A. L. and Coupland, C. (2012): 'From hero to villain to hero: making experience sensible through embodied narrative narrative sensemaking', Human Relations, 65(1): 63-88.

Cunliffe, A. L., Luhmann, J. T. and Boje, D. M. (2004): 'Narrative temporality: implications for organizational research', Organization Studies, 25(2): 261-286.

Czarniawska, B. and Carmelo, M. (2003): 'Consulting as a Liminal Space', Human Relations, 56(3): 267-290.

Czarniawska, B. (2004): Narratives in Social Science Research, London: Sage Publications.

Driver, M. (2009): 'From loss to lack: stories of organizational change as encounters with failed fantasies of self, work and organization', Organization, 16(3): 353-369. 
Flanagan, J. C. (1954): 'The critical incident technique', Psychological Bulletin, 51(4): 327-358.

Goffman, E. (1959): The Presentation of Self in Everyday Life, New York: Doubleday.

Gotsi, M., Andriopoulos, C., Lewis, M. W. and Ingram, A. E. (2010): 'Managing creatives: paradoxical approaches to identity regulation', Human Relations, 63(6): 781-805.

Grosen, S. L. and Knudsen, K. W. (2003): 'Men det er da noget kvinder gør: Relationer mellem arbejdsliv, familieliv og køn' [But that is something women do: Relationships between work-life, family life and gender] Tidskrift for arbejdsliv, 5(4): 41-57.

Hazen, M. A. (1993): 'Towards polyphonic organization', Journal of Organizational Change Management, 6(5): 15-26.

Hochschild, A. (2003): Tidsfeelden: Når familien bliver arbejde og arbejdet bliver familie, Copenhagen: Munksgaard Danmark (Original title: 'The Time Bind', 1997).

Humphreys, M. and Brown, A. D. (2002): 'Narratives of organizational identity and identification: a case study of hegemony and resistance', Organization Studies, 23(3): 421-447.

Ipsen, C. (2006): Vidensarbejderens scerlige arbejdssituation og muligheder for forebyggelse af arbejdsrelateret stress $i$ vidensarbejde' [The special working conditions of knowledge workers and the possibilities of preventing work-related stress in knowledge work] Kgs. Lyngby: DTU.

Ipsen, C. and Jensen, P. L. (2012): 'Organizational options for preventing work-related stress in knowledge work', International Journal of Industrial Ergonomics, 42: 325-334.

Kamp, A., Lund, H. L. and Hvid, H. S. (2011): 'Negotiating time, meaning and identity in boundaryless work', Journal of Workplace Learning, 23(4): 229-242.

Linde, C. (2001): 'The acquisition of a speaker by a story: how history becomes memory and identity', Ethos, 28(4): 608-632.

Linde, C. (2009): Working the Past, Narrative and Institutional Memory, Oxford: Oxford University Press.

Mallett, O. and Wapshott, R. (2012): 'Mediating ambiguity: narrative identity and knowledge workers', Scandinavian Journal of Management, 28: 16-26.

Mishler, E. G. (1999): Storylines, London: Harvard University Press.

Orr, J. E. (1996): Talking About Machines: An Ethnography of a Modern Job, Cornell: Cornell University Press.

Pedersen, A. R. (2008a): 'Narrative identity work in a medical ward-a study of diversity in health care identities', Tamara: Journal of Critical Postmodern Organization Science, $7(1): 38-53$.

Pedersen, M. (2008b): 'Tune in, break down, and reboot—new machines for coping with the stress of commitment', Culture and Organization, 14(2): 171-185.

Rasmussen and Håpnes (2012):'Permanent temporariness? Changes in social contracts in knowledgework'. Nordic Journal of Working Life, 2(1): 5-22.

Renemark, D. (2007): Varför arbetar så få kvinnor med finanser? En studie av vardagen $i$ finanssektorn [Why do so few women work with finances? A study of everyday life in the finance sector]. Gothenburg: BAS.

Riessman, C. K. (2008): Narrative Methods for the Human Sciences, London: Sage Publications.

Riessman, C. K. (1993): Narrative Analysis, London: Sage Publications.

Robertson, M. and Swan, J. (2003): 'Control-what control? Culture and ambiguity within a knowledge intensive firm', Journal of Management Studies, 40(4): 831-858.

Sveningsson, S. and Alvesson, M. (2003): 'Managing managerial identities: organizational fragmentation, discourse and identity struggle', Human Relations, 56: 1163-1193.

Svensson, P. (2009): 'From re-presentation to re-creation: contributing to a radicalisation of linguistically turned interviewing in management studies', Qualitative Research in Organizations and Management: An International Journal, 4(2): 168-185. 
Thisted, L. N. (2003): Mangfoldighedens Dilemmaer [The dilemmas of diversity]. Samfundslitteratur, Copenhagen (PhD series: 2003-2024).

Vaara, E. and Tienari, J. (2011): 'On the narrative construction of multinational corporations: an anternarrative analysis of legitimation and resistance in a cross-border merger', Organization Science, 22(2): 370-390.

\section{End notes}

${ }^{1}$ Didde Maria Humle, Copenhagen Business School, Department of Organization, Kilevej 14 A, 4, DK-2000 Frederiksberg, Denmark. 